DOI: 10.20472/IAC.2017.032.036

REETA RAINA

FORE School of Management, India

\title{
EXPLORING THE EFFICACY OF USING THEATRE TECHNIQUES IN TEACHING BUSINESS COMMUNICATION
}

\begin{abstract}
:
In recent times, more and more teachers in their reinvention of the course, drop the lecture model and are finding alternatives to help students draw a connect between the knowledge acquired in the classroom to their day-to-day life's problems and challenges. The present paper reports about the students' experiences in learning various aspects of communication through theatre techniques. The analysis of the content revealed that the learning through theatre medium was a liberating experience for them that helped them to overcome their negative consciousness and experience the sense of freedom from those archaic irrational biases and prejudices that prevent them from achieving their best. The students reported that this participatory art form helped them in heightening their self-awareness and in developing confidence.
\end{abstract}

\section{Keywords:}

Communication, Theater Technique, Pedagogy, Learning, Teaching ,Efficacy , 